\title{
Análise do entendimento sobre os cuidados necessários para o tratamento da acne em adolescentes de uma igreja da Cidade de São Luís
}

Analysis of the understanding about the care necessary for the treatment of acne in adolescents in a church in the City of São Luís

Análisis del comprensión sobre los cuidados necesarios para el tratamiento del acné en adolescentes en una iglesia de la Ciudad de São Luís

Recebido: 02/10/2021 | Revisado: 08/10/2021 | Aceito: 15/10/2021 | Publicado: 18/10/2021

\author{
Jalmir Coelho Xavier II \\ ORCID: https://orcid.org/0000-0002-8696-4438 \\ Universidade Ceuma, Brasil \\ E-mail: jalmir-xavier@hotmail.com \\ Luís Artur Ferreira de Sousa \\ ORCID: https://orcid.org/0000-0002-7121-1417 \\ Universidade Ceuma, Brasil \\ E-mail: arturluis_ferrer@hotmail.com \\ Marcela Almeida \\ ORCID: https://orcid.org/0000-0002-5101-2074 \\ Universidade Ceuma, Brasil \\ E-mail: marcela.almeida72@gmail.com \\ Maristela Matos Silva \\ ORCID: https://orcid.org/0000-0002-5017-0652 \\ Universidade Ceuma, Brasil \\ E-mail: maristela.mary.s1@gmail.com \\ Milena De Jesus Marinho Garcia de Oliveira \\ ORCID: https://orcid.org/0000-0002-0214-8346 \\ Universidade Ceuma, Brasil \\ E-mail: mile.gmj@gmail.com \\ Monaliza Teresa Campos Sodré \\ ORCID: https://orcid.org/0000-0002-8206-7756 \\ Universidade Ceuma, Brasil \\ E-mail: monalizacampossd@gmail.com \\ Carolina Azevedo Amaral \\ ORCID: https://orcid.org/0000-0002-2155-4454 \\ Universidade Ceuma, Brasil \\ E-mail: carolinaraazevedo@gmail.com \\ Lívia Câmara de Carvalho Galvão \\ ORCID: https://orcid.org/0000-0001-9540-649X \\ Universidade Ceuma, Brasil \\ E-mail: livia.camara@ceuma.br \\ Eduardo Martins de Sousa \\ ORCID: https://orcid.org/0000-0002-2506-169X \\ Universidade Ceuma, Brasil \\ E-mail: edmsousa@hotmail.com
}

\begin{abstract}
Resumo
A acne vulgar é uma patologia que acomete a maioria dos adolescentes sendo de ambos os sexos, é mais predominante no sexo masculino por causa da mudança de hormônios que acontecem nessa fase. Por esse motivo, muitos adolescentes enfrentam sérios problemas psicológicos que geram uma baixa autoestima podendo gerar depressão e isolamento do convívio com a sociedade. Esse estudo tem como objetivo avaliar o entendimento que os adolescentes têm sobre os cuidados necessários para o tratamento da acne. Foi realizada uma pesquisa quanti/qualitativa de caráter exploratório, com adolescentes e jovens na faixa etária entre 14 e 20 anos frequentantes de uma igreja da cidade de São Luís - MA. A amostra do estudo compreendeu 13 participantes que inicialmente foram orientados a responder o questionário préintervenção disponível no programa Socrative by MasteryConnect, sendo que o link para o acesso ao questionário foi disponibilizado na plataforma Google Meet, este questionário contemplava 7 questões relacionadas às principais dúvidas referentes ao tema acne. Após todos responderem o formulário, deu-se início a apresentação da palestra abordando as principais informações sobre o tema, bem como as principais dúvidas do público estudado. Ao fim da palestra o público do estudo foi novamente direcionado ao por meio de link, para que os mesmos respondessem o questionário pós-intervenção com os mesmos questionamentos. Concluí-se com este trabalho que os adolescentes
\end{abstract}


necessitam de orientação sobre a acne no dia-a-dia e a abordagem desse assunto deve ser feita de forma incisiva no cotidiano.

Palavras-chave: Acne; Adolescentes; Conhecimento.

\begin{abstract}
Acne vulgaris is a pathology that affects most teenagers, being of both sexes, it is more prevalent in males because of the change in hormones that occur at this stage. For this reason, many adolescents face serious psychological problems that generate low self-esteem, which can lead to depression and isolation from society. This study aims to assess the understanding that adolescents have about the necessary care to treat acne. A quantitative/qualitative exploratory research was carried out with adolescents and young people aged between 14 and 20 years old, attending a church in the city of São Luís - MA. The study sample comprised 13 participants who were initially instructed to answer the preintervention questionnaire available in the Socrative by MasteryConnect program, and the link to access the questionnaire was made available on the Google Meet platform, this questionnaire included 7 questions related to the main doubts related to the topic of acne. After everyone answered the form, the presentation of the lecture began, addressing the main information on the topic, as well as the main doubts of the studied public. At the end of the lecture, the study audience was again directed to through a link, so that they could answer the post-intervention questionnaire with the same questions. It is concluded with this work that adolescents need guidance about acne in their daily lives and the approach to this subject must be incisive in their daily lives.
\end{abstract}

Keywords: Acne; Teenagers; Knowledge.

\title{
Resumen
}

El acné vulgar es una patología que afecta a la mayoría de los adolescentes, al ser de ambos sexos, es más prevalente en los varones debido al cambio hormonal que se produce en esta etapa. Por esta razón, muchos adolescentes enfrentan serios problemas psicológicos que generan baja autoestima, lo que puede derivar en depresión y aislamiento de la sociedad. Este estudio tiene como objetivo evaluar la comprensión que tienen los adolescentes sobre los cuidados necesarios para tratar el acné. Se realizó una investigación exploratoria cuantitativa / cualitativa con adolescentes y jóvenes de entre 14 y 20 años, que asisten a una iglesia en la ciudad de São Luís - MA. La muestra del estudio estuvo compuesta por 13 participantes que inicialmente fueron instruidos para responder el cuestionario de pre-intervención disponible en el programa Socrative by MasteryConnect, y el enlace para acceder al cuestionario se puso a disposición en la plataforma Google Meet, este cuestionario incluía 7 preguntas relacionadas con las principales dudas relacionadas con el tema del acné. Luego de que todos respondieron el formulario, se inició la presentación de la charla, abordando la información principal sobre el tema, así como las principales dudas del público estudiado. Al final de la conferencia, se volvió a dirigir a la audiencia del estudio a través de un enlace, para que pudieran responder al cuestionario posintervención con las mismas preguntas. Se concluye con este trabajo que los adolescentes necesitan orientación sobre el acné en su vida diaria y el abordaje de este tema debe ser incisivo en su vida diaria.

Palabras clave: Acné; Adolescentes; Conocimiento.

\section{Introdução}

A acne é uma dermatose que acomete principalmente os adolescentes e adultos jovens, sendo uma afecção de origem multifatorial, em que as causas para o seu aparecimento estão relacionadas ao aumento da sudorese, stress, fatores genéticos, trauma mecânico, entre outros (Costa, 2018).

A etiopatogenia da acne está relacionada com alterações na unidade pilossebácea, em que é caracterizado por cinco fatores, sendo eles: uma hipersecreção sebácea; ceratose do canal folicular com consequente estreitamento do canal; colonização bacteriana do folículo sebáceo; liberação de mediadores da inflamação na pele, por conta da alteração do sebo causado pelo crescimento microbiano; fatores individuais. Essa ceratose do canal folicular se torna um ambiente propício para o crescimento microbiano, a Cutibacterium acnes é a bactéria relacionada aos processos inflamatórios da acne (Moreira et al., 2018).

$\mathrm{O}$ acometimento dessa dermatose pode ser manifestado em diversas partes do corpo, especialmente em regiões do corpo em que exista maior quantidade de glândula sebácea, como face (que é a área corporal mais evidente e de maior impacto social), costas, ombros e peito (Gomes, 2020). E sua gravidade é classificada clinicamente conforme o estado em que a mesma se apresentava e que se subdividem em graus: Grau I caracterizado por comedões abertos e/ou fechados, sem processo inflamatório; grau II presença de pápulas e pústulas, já com processo inflamatório, além da presença de comedões; grau III nódulos e cistos, além de pápulas, pústulas e comedões, atividade inflamatória mais intensa; grau IV, acne conglobata, presença de abscessos e fístulas; grau V, acne fulminante, em que ocorrem reações sistêmica, como febre e mal estar (Silva \& Oliveira, 2017). 
As alterações hormonais que ocorre na puberdade quase sempre estão relacionada com o aparecimento da acne, o gênero masculino são os mais frequente acometidos e mais comumente acometidos com manifestações mais graves da acne, em contrapartida, as mulheres apresentam geralmente uma acne mais persistente. $\mathrm{O}$ agravamento da acne acaba por afetar a autoestima dos jovens o que pode comprometer as relações sociais do mesmo, caracterizando a acne principalmente como um problema estético e social (Silva \& Paes, 2017; Costa, 2018).

Os cuidados a serem realizados durante o tratamento/controle da acne visam principalmente evitar as lesões como manchas e cicatrizes. Tais lesões podem ser evitadas e/ou diminuídas com os cuidados adequados principalmente no início do quadro acneico, porém, nem todas as pessoas acometidas pela acne possuem acesso à informação e a ajuda profissional, além de condições econômicas para realizar o tratamento, que na maioria dos casos os cuidados diários poderiam contribuir para o controle deste problema (Silva \& Oliveira, 2017).

Com isso, objetivamos com esse trabalho analisar e orientar quanto ao nível de conhecimento e sobretudo os cuidados necessários para o tratamento da acne em adolescentes de uma igreja da cidade de São Luís - MA.

\section{Metodologia}

Este trabalho consiste em uma pesquisa quanti/qualitativa de caráter exploratório realizada conforme Estrela (2018). No qual ocorreu com adolescentes e jovens na faixa etária entre 14 e 20 anos frequentantes de uma igreja da cidade de São Luís - MA. A abordagem dos adolescentes e jovens deu-se por meio de questionários pré e pós intervenção, sendo que a intervenção foi feita por meio de uma palestra abordando o tema Acne vulgar, que ocorreu de forma on-line através da plataforma Google Meet.

A amostra do estudo compreendeu 13 participantes que inicialmente foram orientados a responder o questionário préintervenção disponível no programa Socrative by MasteryConnect, sendo que o link para o acesso ao questionário foi disponibilizado na plataforma Google Meet, este questionário contemplava 7 questões relacionadas às principais dúvidas referentes ao tema acne. Após todos responderem o formulário, deu-se início a apresentação da palestra abordando as principais informações sobre o tema, bem como as principais dúvidas do público estudado. Ao fim da palestra o público do estudo foi novamente direcionado ao aplicativo Socrative by MasteryConnect por meio de link, para que os mesmos respondessem o questionário pós-intervenção com as mesmas 7 questões, para que assim pudéssemos aferir o conhecimento adquirido na palestra. Essa metodologia foi escolhida por possibilitar a coleta de dados sem o contato direto com o público alvo, dispensando desta forma a análise do Comitê de Ética em Pesquisa (CEP).

As respostas aos questionários pré e pós-intervenção foram tabuladas no programa Microsoft Excel e resultaram em dois gráficos de distribuição de frequências, nomeados como figura 1 referente ao conhecimento pré-intervenção e figura 2 , referente ao conhecimento pós-intervenção.

\section{Resultados}

A amostra compreendeu 13 adolescente e jovens entre 14 e 20 anos, sendo 9 do sexo feminino e 4 do sexo masculino e a aplicação do formulário antes e depois da palestra foi fundamental para a identificação do aproveitamento do que foi exposto durante a apresentação.

Na Figura 1 observamos a avaliação inicial do conhecimento sobre a acne (Questionário pré intervenção). 


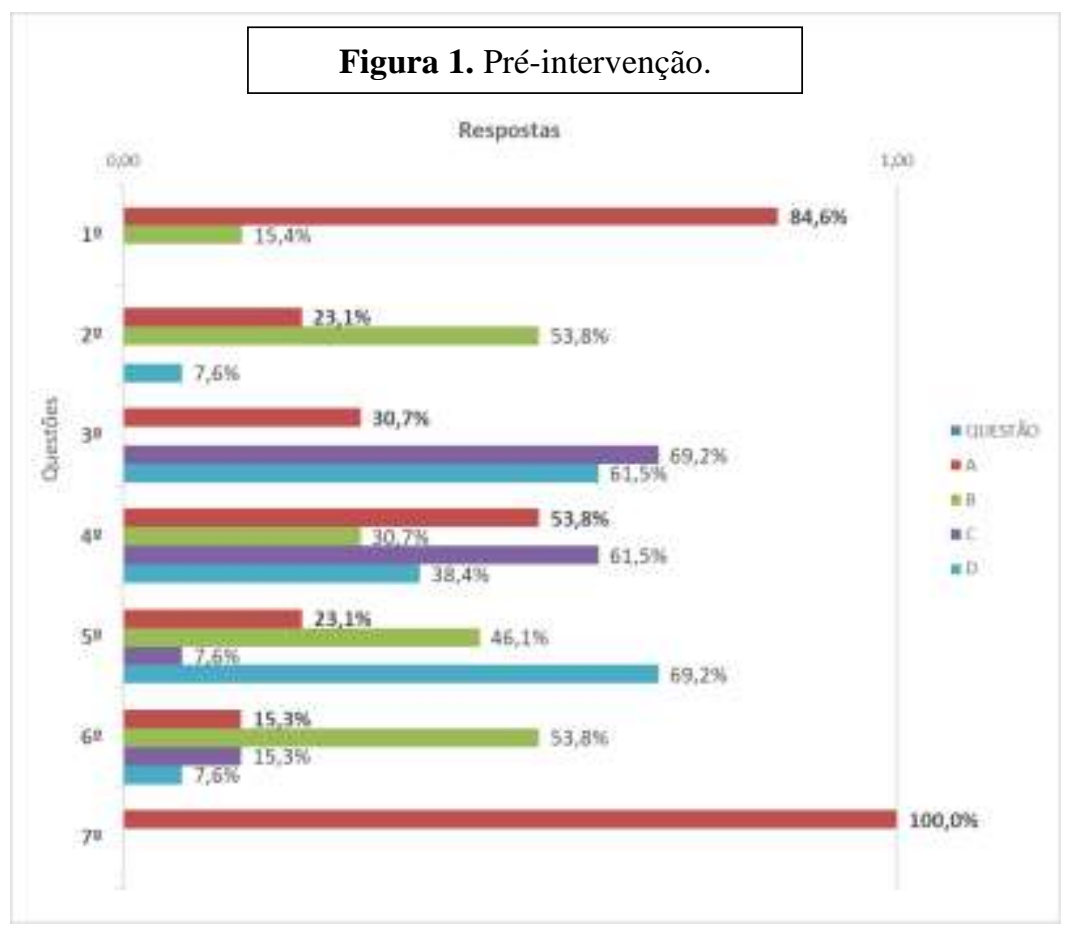

Fonte: Autores.

Ao ser aplicado o formulário antes da palestra, teve-se os seguintes resultados: na primeira questão do formulário foi questionado sobre a definição de acne onde 84,6\%(11/13) definiram marcando a alternativa A como sendo pontos pretos com bolinhas inflamadas, 15,4\% (2/13) marcaram a alternativa B como sendo coceira na pele seguida de vermelhidão e nenhum dos avaliados optaram pelas alternativas C e D, evidenciadas como: não sei mas as pessoas já falaram que eu tenho e doença grave, respectivamente. Os participantes poderiam optar por mais de uma alternativa.

Na segunda questão, ao serem questionados sobre qual tipo de microrganismo ocasiona a acne, 53,8\% (7/13) marcaram a opção correta, letra B que é por uma bactéria, seguido da opção A com o quantitativo de 23,1\% (3/13) sendo o fungo, a letra $\mathrm{D}$ com 7,6\% (1/13) sendo causado por um verme e a letra $\mathrm{C}$ que seria por vírus nenhum dos participantes optaram por essa alternativa. Os participantes poderiam optar por mais de uma alternativa.

Em relação a terceira questão o questionamento foi sobre como a acne pode surgir, 69,2\% (9/13) evidenciaram a alternativa C: por causa da sujeira na pele; 61,5\% (8/13) selecionaram a letra D, por causa da oleosidade da pele; 30,7\% (4/13) pela alternativa A: proveniente da má alimentação e nenhum dos participantes marcaram a alternativa B: relacionado com a utilização de protetor solar. Os participantes poderiam optar por mais de uma alternativa.

Sobre a quarta questão foi perguntando sobre qual seria a predominância da alimentação dos participantes. 61,5\% (8/13) optaram pela alternativa C composta por doces e refrigerante; 53,8\% (7/13) marcaram a alternativa A que seria por frituras e gorduras; 38,4\% (5/13) escolheram a alternativa D laticínios (leites e seus derivados); 30,7\% (4/13) marcaram a letra B verduras, frutas e legumes. Os participantes poderiam optar por mais de uma alternativa.

Na Figura 2 observamos a avaliação final do conhecimento sobre a acne (Questionário pós intervenção). 


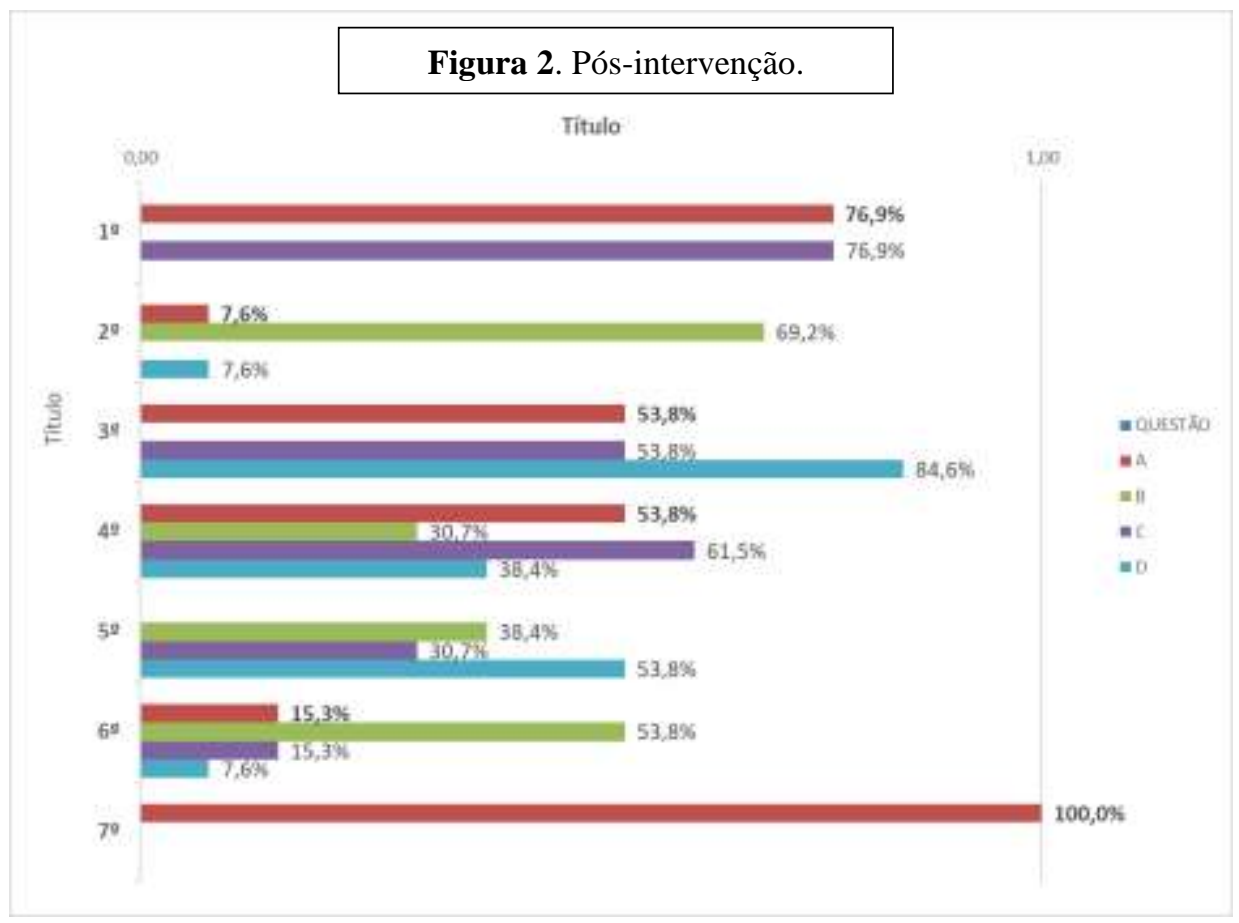

Fonte: Autores.

$\mathrm{Na}$ quinta questão foi avaliado sobre os conhecimentos que os participantes tinham sobre o que melhoraria a acne e as respostas foram: 69,2\% (9/13) marcaram a alternativa D que seria tratamentos para retirada de oleosidade; 46,1\% (6/13) optaram pela alternativa B sendo como a utilização de pomadas antinflamatórias; 23,1\% (3/13) marcaram a alternativa A que continha o uso de mistura caseira do tipo limão com açúcar; 7,6\% (1/13) marcaram a alternativa $C$ evidenciando o uso de aparelho como alta frequência e o laser. Os participantes poderiam optar por mais de uma alternativa.

A sexta questão foram questionados se já haviam deixado de sair ou receber visita por e 53,8\% (7/13) responderam que não marcando a alternativa $B, 15,3 \%$ (2/13) responderam que sim, optando pela alternativa $A, 15,3$ (2/13) marcaram a letra $C$ que muitas vezes e 7,6\% (1/13) marcaram a opção $\mathrm{D}$, poucas vezes.

E na última questão $100 \%$ dos participantes afirmaram que a acne era um assunto de seu interesse quando questionados se o assunto acne os interessava.

Ao ser aplicado o mesmo questionário ao final da palestra tivemos os seguintes resultados: Na primeira questão sobre o conceito de acne 76,9\% (10/13) marcaram a letra C que seria por conta do acúmulo de oleosidade ocasionando obstrução dos óstios; 76,9\% (10/13) optaram pela letra A que seria pontos pretos com bolinhas inflamadas e as letras B e C com percentual equivalente a zero porcento. Os participantes poderiam optar por mais de uma alternativa.

Na segunda questão que foi perguntado sobre que tipo de microrganismo ocasiona a acne 69,2\% (9/13) dos participantes marcaram a opção correta, letra B bactéria; 7,6\% (1/13) marcaram as alternativas A e D, fungo e verme respectivamente e nenhum dos participantes optaram pela opção $\mathrm{C}$ vírus. Os participantes poderiam optar por mais de uma alternativa.

Ao responder novamente a terceira questão sobre o surgimento da acne, 84,6,8\% (11/13) marcaram a letra D que é ocasionada pela oleosidade da pele, 53,8\% (7/13) marcaram A e C onde seria através da má alimentação e em relação a sujeira da pele, respectivamente e nenhum escolheram a letra B que seria através do uso de protetor solar. Os participantes poderiam optar por mais de uma alternativa.

$\mathrm{Na}$ quarta questão ao serem questionados sobre a predominância da composição de sua alimentação, 61,5\% (8/13) optaram pela alternativa $\mathrm{C}$ composta por doces e refrigerante; $53,8 \%$ (7/13) marcaram a alternativa A que seria por frituras e 
gorduras; 38,4\% (5/13) escolheram a alternativa D laticínios (leites e seus derivados); 30,7\% (4/13) marcaram a letra B verduras, frutas e legumes. Sendo semelhante às respostas do primeiro questionário. Os participantes poderiam optar por mais de uma alternativa.

Ao serem questionados novamente sobre o que melhoraria a acne na questão cinco, 53,8\% (7/13) respondeu que seria tratamentos para retirada de oleosidade, letra D. 38,4 (5/13) optaram pela alternativa B com a utilização de pomadas antiinflamatória; 30,7\% (4/13) marcaram a alternativa $\mathrm{C}$ uso de aparelho como alta frequência e laser e nenhum dos participantes marcaram a alternativa A que descrevia o uso de misturas caseiras limão e açúcar.

Na sexta foram questionados se já deixaram de sair ou receber alguém por conta da acne e 53,8\% (7/13) responderam que não marcando a alternativa $\mathrm{B}, 15,3 \%$ (2/13) responderam que sim, optando pela alternativa $\mathrm{A}, 15,3(2 / 13)$ marcaram a letra C que muitas vezes e 7,6\% (1/13) marcaram a opção D, poucas vezes.

E novamente questionados se acne era um assunto que os interessava $100 \%$ marcaram que sim.

\section{Discussões}

Podemos evidenciar os resultados obtidos relacionados a primeira pergunta, onde questiona sobre o conceito de acne, obtendo como respostas de maior relevância na pré-intervenção, definido por $84,6 \%$ dos participantes como sendo pontos enegrecidos contendo processo inflamatório local (bolinhas vermelhas), e 15,4\% dos participantes optaram como sendo provenientes de vermelhidão e coceira. Essas informações se relacionam com a pesquisa segundo Moreira et al (2018), disseminando sobre a etiologia da acne, evidenciando colonização bacteriana no folículo pilossebáceo, com consequente liberação de mediadores inflamatórios, resultando em graus de acne, que podem ir do Grau I até ao Grau V, que dependendo de sua gravidade, podemos perceber inflamação local, deixando a aparência da pele em algumas regiões com aspecto avermelhado e sensível.

Após coleta dos resultados sobre o mesmo assunto abordado (conceito de acne), podemos ressaltar na pós intervenção, que grande parte dos participantes mantiveram pela resposta consistindo no processo de formação e conceituação da acne, a opção que seria pontos enegrecidos com bolinhas inflamadas, onde 76,9\% dos participantes optaram por esta resposta, havendo uma redução pequena comparado ao percentual no processo de pré intervenção. Segundo Moreira et al (2018) e Moreira (2019), a acne é definida como uma dermatose que acomete a pele, envolvendo em sua patogênese um aumento na produção da glândula sebácea, anormalidade no processo de queratinização com estreitamento do canal folicular, deixando um ambiente propício para proliferação bacteriana, resultando em lesões não inflamatórios, evidenciando os comedões, e lesões não inflamatórias, como pápulas, pústulas, nódulos e cistos.

Podemos perceber que através da palestra, 76,9\% dos participantes também optaram como resposta em decorrência da conceituação da acne, lembrando que os mesmos poderiam escolher mais de uma opção, sendo proveniente do acúmulo de oleosidade, ocasionando obstrução dos óstios. Este resultado é ratificado por Tassinary et al (2019), sendo um dos fatores que acometem no processo de patogênese da acne, ocorrendo através da hipersecreção do sebo produzido pela glândula sebácea ficando retido no óstio do folículo pilossebáceo, procedendo da hiperproliferação epitelial folicular e retenção dos queratinócitos, fatores que contribuem para a obstrução dos orifícios (ósteos).

Os resultados coletados referente a segunda questão, onde os participantes foram questionados sobre o microorganismo que ocasiona a acne, podemos relatar que a maioria dos participantes, tanto na pré intervenção ( $53,8 \%)$ quanto na pós-intervenção $(69,2 \%)$ optaram pela alternativa correta, ocasionada por uma bactéria. Segundo estudos, este resultado está de acordo com Fournière (2020), evidenciando um dos principais microorganismos envolvidos na patogênese da acne, sendo o Cutibacteruim acnes (C. acnes), anteriormente conhecido como Propionibacterium acnes (P. acnes). Os fungos Malassezia, assim como o 
Cutibacterium, Staphylococcus, Corynebacterium, Pseudomona foi citado por Moreira (2019) como sendo a flora comensal do folículo pilossebáceo.

Cutibacteruim acnes (C. acnes) é um tipo de bactéria mais comumente encontrado na acne, por ser influenciado por inúmeros fatores presentes no desenvolvimento dessa dermatose, que ocasiona uma disbiose na microbiota da pele com consequente proliferação bacteriana, sendo evidentes características como anaeróbica ou microaerófila gram-positiva, tendo como habitat as unidades dos folículos pilossebáceos (Neves, 2015; Gameleira, 2020; Fournière, 2020).

Ao serem questionados sobre como a acne pode surgir, na pré intervenção cerca de 69,2\% evidenciaram que era por conta da sujeira, seguido de $61,5 \%$ que optaram pela oleosidade da pele, já na pós-intervenção a grande maioria $(84,6 \%)$ já optaram pela oleosidade da pele seguida de sujeira e má alimentação $(53,8)$, corroborando com o que foi apresentado na palestra. A causa da acne é multifatorial, onde a hipersecreção sebácea é um dos principais fatores, uma vez que pode causar uma ceratose do canal folicular e consequente estreitamento do folículo propiciando o crescimento microbiano seguido de inflamação, os fatores individuais influenciam todo esses processos (Moreira et al., 2018). Estudo publicado por Silva \& Oliveira (2018), mostrou a grande influência que a alimentação pode ter no agravamento da acne, uma vez que, no estudo foi evidenciado que o grupo que tinha acne tinha uma alimentação com alto índice glicêmico em comparação com o grupo controle (sem acne).

Podemos observar com os resultados coletados na questão 4 que fala a respeito da composição alimentar, $(61,5 \%)$ dos participantes consomem alimentos ricos em açúcar (doces e refrigerante). Segundo Roschel et al (2018), alimentos que contém açúcar afeta a homeostase metabólica dos folículos sebáceos e justifica que este tipo de alimento sinaliza certos hormônios a estimular o crescimento de células no organismo, incluindo o folículo sebáceo. (53,8\%) informaram que sua dieta é rica em fritura e gordura. Conforme Araújo et al (2011) em um estudo publicado mostrou que o consumo de gordura, açúcar e fast foods estão relacionados positivamente com a acne em adolescentes e os adolescentes que não apresentavam acne tinham hábitos alimentares mais saudáveis, com isso a ingestão de alimentos como bolo, refrigerantes, salsichas, hamburgueres e bolos foram associados ao risco aumentado desta afecção.

Em relação a questão 5 sobre o que eu sei que melhora a acne, (53,8\%) optaram por tratamentos para retirada da oleosidade. Segundo Coelho (2016), a limpeza de pele não se configura como apenas uma técnica que visa o tratamento da acne, mas sim, é um auxiliar no tratamento de acne vulgar, a qual age junto com tratamentos medicamentos e produtos que tratam ou previnem a evolução das lesões inflamatórias. $(38,4 \%)$ optaram por tratamentos com pomadas antiinflamatória. De acordo com Da Silva (2018), algumas orientações devem ser feitas por profissionais da área, o paciente não deve manipular a lesão, pois existe o risco de infeccionar, inflamar ou deixar cicatriz. O recomendado é utilizar produtos de higiene para pele acneica ou oleosa, todavia a limpeza excessiva da pele pode ser prejudicial à pele causando irritação ou agravamento das lesões. A acne pode melhorar quando a pessoa é exposta moderadamente ao sol, porém a exposição excessiva tende a piorar o quadro.

Quanto aos resultados obtidos na pesquisa para a 6 pergunta (você já deixou de sair ou de receber alguém por conta da acne), as respostas se mantiveram as mesmas para ambos os questionários e nos chamou atenção que 15,3\% dos participantes responderam que sim. Este resultado corrobora com o encontrado por Carvalho (2020), em pesquisa que analisou o impacto da acne na vida social de estudantes universitários e quando perguntado aos entrevistados se deixaram de comparecer a algum compromisso social por não se sentirem adequados por possuírem acne, constataram que 15\% das mulheres e 13,33\% dos homens já haviam faltado a algum compromisso por não se sentirem confortáveis.

Tal fato pode ser explicado pela adolescência ser considerada como um período instável tanto do ponto de vista físico quanto psicológico e nesse período o jovem sente a necessidade de agradar outras pessoas. É sabido que o desenvolvimento da acne pode levar a repercussões psicológicas, como a perda da autoestima, distorção da imagem corporal, constrangimento, isolamento social, revolta, ansiedade, depressão entre outras (Teixeira et al., 2012). 
Quanto a última pergunta, os participantes afirmaram por unanimidade (100\%) tanto na pré-intervenção quanto na pósintervenção, que a acne é um assunto de interesse. Devemos levar em consideração que praticamente todo indivíduo tem algum grau de acne na adolescência e mesmo que muitos casos tenham resolução espontânea na fase de adulto jovem, ocasionalmente a doença pode persistir por mais tempo, podendo até mesmo, em alguns casos, deixar cicatrizes para a vida toda (Peric et al., 2013).

Tendo em vista os diversos malefícios, sobretudo, as alterações inestéticas causadas pela acne, é cada vez mais notório o interesse dos adolescentes por este assunto, estando o mesmo atrelado principalmente ao fator estético, que é de suma importância para os adolescentes, já que implica na sua aceitação em grupos de socialização (Franco, 2021).

\section{Conclusão}

Concluímos com este trabalho que os adolescentes necessitam de orientação sobre a acne no dia-a-dia e a abordagem desse assunto deve ser feita de forma incisiva no cotidiano. Poucos procuram orientações sobre os cuidados necessários para o tratamento da acne e quando procuram nem sempre ocorre em fontes confiáveis, por isso a necessidade deste tema ser inserido de uma forma didática e confiável aos adolescentes, visto o grande impacto que o conhecimento adequado de como tratar essa dermatose gera nos indivíduos afetados, possibilitando que os mesmos enfrentem e consigam superar as transformações geradas pela acne.

\section{Referências}

Araújo, A. P. S., Delgado, D. C \& Marçal, R. (2011). Acne diferentes tipologias e formas de tratamento. VII Encontro Internacional de Produção Cientifica. Jarezinho-PR.

Carvalho, P.R.S. (2020). O impacto da acne na vida social de estudantes universitários. Temas em Saúde, edição especial.

Coelho, E. M. (2016). Avaliação da qualidade de vida de pacientes com acne vulgar antes e após o tratamento com isotretinoína oral. (Monografia apresentada à Universidade Federal de Santa Catarina).

Costa, I. V. (2018). Acne vulgaris no adulto. Dissertação (Mestrado Integrado em Medicina) - Instituto de Ciências Biomédicas Abel Salazar, Universidade do Porto, Porto.

Da Silva, M. A. M., Paes, S. N. D. (2018). Estudo da relação entre a alimentação e a acne vulgar. Cadernos UniFOA, 12(35), $123-133$.

Estrela, C. (2018). Metodologia Científica: Ciência, Ensino, Pesquisa. Editora Artes Médicas.

Franco, G. E. A. (2021). Acne: aspectos microbiológicos e terapia estética conservadora. Revista brasileira interdisciplina saúde - ReBIS, $3(1), 6$-12.

Fournière, M. (2020). Staphylococcus epidermidis and Cutibacterium acnes: two major sentinels of skin microbiota and the influence of cosmetics. Microorganisms, 8(11), 1752.

Gameleira, J. G. (2020). Microbiota e estética: intervenção nutricional e alterações dermatológicas. Semana de Pesquisa do Centro Universitário Tiradentessempesq-Alagoas, n. 8 .

Gomes, L. P. (2020). Influência dos cuidados com a pele no controle da acne em adolescentes. Revista eletrônica interdisciplinar, 12(2), 013-022.

Moreira, F. S, Melo, M. M. A, Neres, I. A, Azevedo, M. L. G \& Pessoa, C. V. (2018). Uso de esfoliantes químicos no tratamento da acne. Mostra científica da farmácia, Quixadá, 5(1).

Moreira, C. J. S. (2019). Acne: relação hospedeiro-patógeno. Tese de Doutorado.

Neves, J. R. (2015). Propionibacterium acnes and bacterial resistance. Surg. Cosmet. Dermatol., 7, 27-38.

Roschel, G. G., Silva, A. H. W., Kutz, N. A., Miotto, T., Silva, N. M. da, \& Salgueiro, M. M. H. A. O. (2018). Acne e consumo alimentar: análise de fatores associados em uma clínica particular. Life Style, 5(1), 11-23. https://doi.org/10.19141/2237-3756.lifestyle.v5.n1.p11-23.

Peric, J. (2013). Prevalence and quality of life in high school pupils with acne in Serbia. Vojnosanit Pregl, 70(10), 935-939.

Silva, V. R. S., \& Oliveira, P. S. (2018). Acne na adolescência e a intervenção estética. Trabalho de Conclusão de Curso (Tecnologia em Estética e Imagem Pessoal) - Universidade Tuiuti do Paraná, Curitiba.

Silva, M. A. M. \& Paes, S. N. D. (2017). Estudo da relação entre a alimentação e a acne vulgar. Cadernos UniFOA, Volta Redonda, (35), 123-133. 
Research, Society and Development, v. 10, n. 13, e439101321346, 2021

(CC BY 4.0) | ISSN 2525-3409 | DOI: http://dx.doi.org/10.33448/rsd-v10i13.21346

Tassinary, J., Sinigaglia, M., \& Sinigaglia, G. (2019). Raciocínio clínico aplicado a estética facial. Estética experts.

Teixeira, V., Vieira, \& R., Figueiredo, A. (2012). Impacto psicossocial da Acne. Sociedade Portuguesa de Dermatologia e Venerologia, 70(3), $291-296$. 